\title{
Setting up stall in the market place: psychotherapy in a state health service
}

\author{
Christopher Maloney
}

\begin{abstract}
Public sector psychotherapy differs from private practice in tits explictt responsibility for a population. This has major implications, with the need to ration a scarce resource inevilably affecting clinical practice. De facto rationing has existed within the National Health Service (NHS) for years, and the 'unconscious' processes Involved must be made expliclt if NHS peychotheraplsts are to deal with their broader responsibilities, and influence current changes in the Health Service. Resource issues and the related psychological conflicts shape clinical practice and thus theorefical concepts. The effects on practice could be seen as a series of unhappy compromises, or a stimulus to the creative development of a specific NHS peychotherapy, as envisaged by Sigmund Freud.
\end{abstract}

In September 1918, barely six weeks before the end of our century's first long, bloody, high technology war, Freud spoke to the Fifth International Psycho-Analytical Congress in Budapest. This was a regrouping after years of trauma and separation, and a look towards the future. After some talk of technical issues he spoke of a situation:

"which belongs to the future ... that will seem fantastic to many of you, but ... which we should be prepared for in our minds. The poor man (will) have just as much right to assistance for his mind as he now has to the life-saving help offered by surgery ... institutions or out-patient clinics will be started, to which analytically trained physicians will be appointed ... (and) such treatments will be free. (Freud, 1918)"

Freud's scenario is no longer science fiction. The pessimist, though, might fear our independent, analytically oriented state service becoming as much a part of history as the Budapest congress.

\section{Two models of psychotherapeutic care} Dynamic psychotherapy as a whole has evolved through a complex interplay of theoretical, cultural, social and economic forces. Such forces are currently at play through the National Health
Service (NHS) resource crisis, and management reforms. The structure of, and demands upon, a service have a great influence on clinical practice, and affect the development of theoretical concepts: administrative structures shape thought. The current changes will thus affect both the administrative and theoretical development of psychotherapy within our state Health Service. Psychotherapists have an understanding of processes in individuals and groups which will be tested in the current upheaval; the challenge is to preserve a speciality whose value has been recognised late, and remains controversial, while enhancing the creative potential of the changes that occur.

Psychotherapy, unlike other medical specialities, was not comprehensively nationalised in 1948. The analytic private sector has remained, embodying a particular approach to treatment and model of practice, and exerting a major influence on the training of psychotherapists for the NHS. This 'analytic world', although divided, remains a vigorous source of clinical approaches to, and insights about, the problems our patients bring. The application of these clinical methods and theoretical concepts in NHS practice has often entailed adopting the accompanying administrative model, with the main difference being that the patient does not pay. This neglects an essential difference between the public and private sectors.

The private practitioner fills vacancies until none remain. His responsibilities are to the people currently in treatment. This perspective can be broader, as with the social concerns of some institutions, but it need not necessarily be so. By contrast, in NHS work, there is explicit responsibility for a population, providing to each according to their need and ability to benefit. Where resources are limited, definitions of 'need' and 'ability to benefit' are all-important criteria for deciding who benefits from a limited treatment resource. The offer of treatment (and its type and length) depends both on the individual's own clinical need and the comparable needs of others. This is not a necessary part of the private 
practitioner's assessment. The private sector has never evolved theoretical or administrative methods of dealing with an important conflict facing today's NHS psychotherapists, nor have the pyschological consequences of this conflict been widely addressed.

In Budapest Freud saw the economic problem of a state service quite clearly:

“... even by working very hard, each can devote himself in a year to only a small number of patients. Compared to the vast amount of neurotic misery which there is in the world, and perhaps need not be, the quantity we can do away with is almost negligible. Besides this, the necessities of our existence limit our work to the well-to-do classes .... (Freud, 1918)"

There is much to do, psychotherapy is labourintensive, and the psychotherapist's labour is not cheap.

\section{Avoiding the resource issue}

In the past, in common with other medical specialities, NHS psychotherapy has avoided dealing in a rigorous and explicit way with effects of limited resources on clinical practice. The NHS is a complex system, in von Bertalanffy's (1968) terms that has, over time, evolved "checks and balances" that control demand for scarce resources, and so maintain homeostasis. These processes have arisen within the system itself, rather than having been deliberately designed, either by administrators or clinicians. They thus operate outside the explicit responsibility of any particular individual or group.

Need and provision interact within a structure, usefully modelled by Goldberg \& Huxley (1980). A patient has a 'pathway' through a health care system, determined by the outcome at a series of 'filters', such as a general practitioner (GP) consultation, or out-patient visit. At each, a decision is made, explicitly or implicitly, as to the person's future involvement with the system. i.e. the route their pathway will take. Thus demand is controlled at the filters. A small shift in the percentage of patients with clear psychological distress referred by a GP to a secondary service could create an unmanageable deluge of work (Dean, 1988). Such overwhelming shifts, for the most part, do not occur, suggesting that powerful homeostatic mechanisms are at play.

Empirical work on the referral process has particularly examined referral from general practice to psychiatric services. Kaeser \& Cooper (1971) summarised a comprehensive study of referrals to the Maudsley hospital: "an absence of firmly established clinical indications ... the selection of cases for specialist care is heavily influenced by non-clinical factors".
This has been repeatedly demonstrated by other workers (Williams \& Clare, 1986).

One well-known service-related factor is the waiting list: a long waiting time is well established as a crude but effective controller of demand on services. There are, however, more subtle, and difficult to identify, influences. Important examples are described in sociological studies of the use and availability of health services (Tuckett, 1976a). Deep-seated differences in attitudes and behaviour between cultures, and socioeconomic classes, influence help-seeking behaviour, and also the type of help that is likely to be provided (Tuckett, 1976b). Tudor Hart's Inverse Care Law is a poignant expression of these effects: the availability of good medical care varies inversely with the need for it in the population served (Tudor Hart, 1971). This is important taken with the conclusions of the Black report on inequalities in health (Black et al, 1982), that ill health of all types is more prevalent in the lower socioeconomic classes, and in ethnic minorities. The long-standing accusation levelled against pyschotherapy, of attending preferentially to the higher social classes, is true of the whole range of medical care.

\section{One service's experience}

The powerful effect of filters can be illustrated from the experience of one well-established department in the Anglia and Oxford Region. Referrals, approximately 200 a year at the time of the study, were a highly selected group, drawn from a catchment population of 545000 people, and occasionally beyond. A study of referral pathways (Maloney, 1993) showed that all patients had passed through one professional filter, and $55 \%$ had passed through two or more. Further significant filtering occurred once in the department. Of 599 consecutive referrals between January 1988 and June 1991, 273 (45.6\%) went into treatment, and $75(12.5 \%)$ were declined assessment or treatment on clinical grounds. The remaining 251 (41.9\%) withdrew from, or were unavailable for, treatment for a wide variety of reasons not directly due to a clinician's decision.

A study of these patients assessed from 198891 showed significant bias towards the higher social classes, judged using the Registrar General's classification of Father's occupation (Office of Population Censuses and Surveys, 1980): $62.1 \%$ of patients were from social classes 1 and 2 , whereas these groups make up only $31.1 \%$ of the local population (OPCS, 1982). An even greater bias was seen in ethnic origin, with 96.3 of patients of white Caucasian origin, despite a rich ethnic mix in the urban areas. The study of pathways to care clearly showed no significant difference in the social class or ethnic structure of 
the groups receiving and not receiving treatment. Thus the blases seen are a product of the filtering before contact with the department, and occur as a result of the subtle, undefined process already discussed.

These figures are typical of many psychotherapy services, and raise important issues about clinical practice. Are we seeing a legitimate and effective selection of the patients most in need of, and able to benefit from our services? Alternatively, are our patients selected by mechanisms whose main funciton is the homeostasis of the system itself, and which might perpetuate injustice and inequality?

An appreciation of the way demand is already being controlled, and the extent to which this is on legitimate clinical grounds, is essential if the provision of psychotherapy for communities is to be taken seriously. Taking this responsibility will actually face us with difficult choices, and it may be hard to feel that the right decisions are being made. It is a complex and abstract task, in a sense doomed to failure, since need far exceeds the possible provision. By contrast in private practice one can provide adequate, or even excellent, therapy for a small group of individuals without a necessary sense of depriving others as a result. The new public sector psychotherapist can no longer avoid this psychic pain in this way.

\section{Changing responsibilities and changing structures}

One of the central aims of psychotherapy is to increase the autonomy of the individual (Holmes \& Lindsay, 1989). For the public sector psychotherapists, the working environment of a 'state service' can be antithetical to this way of thinking, and, indeed, encourage 'neurotic' solutions to seemingly insoluble problems, particularly in times of shortage and change. Individuals in the service often experience tensions in their relationship with the structure as feelings of persecution and lack of autonomy. This bears on the consultation role of the NHS psychotherapist: a particular, and special responstbility to foster autonomy and creativity in a possible unfavourable environment, in the interests of the service itself.

In addition, the administrative base of the clinical responsibility to the population is changing. The 'purchaser-provider split', and the responsibility of the provider to meet the purchaser's requirements, is replacing a more diffuse responsibility. As yet, however, the practical meaning of the new structures is uncertain. Definition of the provider, and the nature of what is to be provided, is, it seems, to be arrived at locally.
Psychotherapy is not recognised as an essential speciality in the same way as general surgery: we have not come quite so far as Freud prophesised. Also, the position of the speciality vis-à-vis mental health services as a whole is not resolved. Because of their size, and relatively small numbers, it is unlikely that existing departments of psychodynamic psychotherapy within the NHS will gain independent status as 'provider' units. If not, one immediate option is to accept a position as a sub-speciality of psychiatry. Alternatively, strong links could be developed with other psychological treatment services, such as those provided in many areas by clinical psychology services. The unifled 'psychological treatment service' would, through a common administrattve structure and point of entry for patients, provide a range of psychotherapies according to individual needs and available resources with practitioners from a wide range of theoretical orientations.

Underlying these alternatives is an important philosophical issue. Does analytically based psychotherapy offer an alternative vlew of human suffering to the medico-pharmacological model or is it simply a "treatment modality'? Status as a 'sub-speciality' might come to mean that the relevance of a psychotherapeutic approach was circumscribed and, importantly, defined in terms of a very different model. Changes in a service's structure have profound implications for the clinical practice. For psychotherapists, both the type of patients we see, and the way we treat them, may change, and as our clinical experience changes, so, inevitably, will our theoretical perspective: its evolution is directed by our daily work. Apparently easy administrative solutions may carry much in their wake.

The danger of the current reforms is that the solution to economic problems will be based on financial expediency alone (Ham, 1993). Heightened competition within the NHS could threaten the future funding of a controversial service such as psychotherapy. Medical specialities have always competed between themselves for funds; traditionally the 'glamour' specialitles have done well. In the past society has shown less concern for chronic psychological distress than for physical illness. More optimistically, there are professed aims of making services more responstve to the wants and needs of the people. A shift in priorities is already occurring. partly related to the increased emphasis on the needs of primary carers (Ham, 1993). This offers hope for the survival and growth of our speciality: GPs, and their patients, may well demand ready access to good quality psychological treatments.

Resistance to such change may well come from within, as well as outside the psychotherapy world, particularly from those wedded to a different model of the psychotherapy service, 
more focused on the individual alone. It has been said that adoption of brief treatment programmes represents a dangerous compromise of analytic integrity, and simply institutionalises and gives tacit approval to a two-tier system of private and public sector psychotherapeutic care. The contention of this paper however, is that there is a difference between the two, because of an important, and legitimate, dimension of the public sector therapist's work. It is inevitable that, to cater for more, each must be given less. One might adopt the position that our energies, should be devoted to making a fuss about the differences between NHS and private care, bringing the former more in line with the latter. This denies the reality of a political and cultural environment where the battle is to establish and maintain any psychotherapy provision.

Some consultant psychotherapists work in both public and private practice, and so have first-hand experience of the two sectors. The vital question is whether this is an uneasy compromise, or a channel for cross-fertilisation. As Freud (1918) so clearly saw, the two models are different, not in opposition. Indeed, the psychotherapist as administrator of a service will always have to hold the two in a tension. There is an important responsibility to the patient in our care, just as in private practice: and in the immediate treatment encounter there will be little difference in the two approaches. The extra dimension of service provision need not necessarily conflict with the primary responsibility to one's patient, once the issues of what can be provided have been thought through. There will always be a place for long-term analytic therapy in the NHS: these arguments do not question this. It cannot, however, be the basic, first-line provision. This was in fact Freud's (1918) position:

"We shall be faced by the task of adapting our technique to the new conditions (of a state service) ... Often, perhaps, we may only be able to achieve anything by combining mental assistance with some material support ... It is very probably, too, that the large-scale application of our therapy will compel us to alloy the pure gold of analysis freely with the copper of direct suggestion ... But. whatever form this psychotherapy for the people may take, whatever the elements out of which it is compounded, its most effective and most important ingredients will assuredly remain those borrowed from strict and untendentious psychoanalysis".

Psychodynamic thought takes place within a matrix that owes much to the service within which psychotherapists work. NHS psychotherapy is being reshaped by the current reforms, and will grow increasingly different from analytic private practice as a result. The theoretical changes are already occurring. The development of cognitive analytic therapy (Ryle, 1990), a structured short-term psychotherapy with an emphasis on straightforward communication of analytic insights, is an important and imaginative attempt to confront the economic difficulties of a psychotherapy service, while using the constraints constructively. The test of the approach will be its durability and continued relevance to clinical practice, but its prospects are strengthened by Ryle's anticipation of the issues with which state psychotherapy would eventually grapple.

Many of the new demands on NHS practitioners are onerous, yet offer a stimulus for rigorous thought and self-examination of the kind central to the psychoanalytical method. Already significant changes in attitude are occurring. The Department of Health has commissioned a review of psychotherapy services throughout the country, and also a literature review looking at the effectiveness of particular psychotherapies, according to psychiatric diagnoses. Although operating within a particular medical model, this promises much for the acceptance of psychotherapy as an integral part of mental health services. Psychotherapy research itself has undergone a sea change in the last ten years, moving towards research based in the paradigm of psychological therapy itself - and no longer simply attempting self-justification using methodology more appropriate to a drug trial.

As has been discussed, the practice of audit, so essential to the fulfilment of our administrative responsibilities, is also a vital extension of the clinical work, with far reaching consequences for the work itself. Glenys Parry (1992) produced a comprehensive review of research, audit and service evaluation and the field is expanding.

The focusing of attention on service issues can be experienced either as a frustration, with a series of unhappy compromises preventing us from working and thinking the way we want to, or as a creattve force. Conflict and psychological pain will have to be faced: one of the tenets of psychoanalysis is that this is a creattve process. Meticulous attention to our service structures, and their implications, is tilling the soil out of which the next generation of theoretical advances will grow.

\section{References}

von Bertalanffy, L. (1968) General Systems Theory. New York: Brazillier.

BLACK, D., MORRIS, J. N.. SMmr, C., et al (1982) The Black Report. London: Penguin.

DEAN, C. (1988) Psychiatry in general practice. In Companion to Psychiatric Studies (eds R. E. Kendell \& A. K. Zealley), pp. 634-647. Edinburgh: Churchill Livingstone. 
FREUD, S. (1918) Lines of advance in psychoanalytic therapy. In Collected Works, Vol. XVII (ed. J. Strachey). pp. 159-168. London: Hogarth Press.

GOLDBERG, D. \& HuXLEY, P. (1980) Mental Illness in the Community: the Pathway to Psychiatric Care. London: Tavistock.

HAM, C. (1993) How go the NHS reforms? British Medical Joumal, 306, 77-78.

HOLMES, J. \& LINDSAY, R. (1989) The Values of Psychotherapy. Oxford: Oxford Untversity Press.

KAESER, A. \& COOPER, B. (1971) The psychiatric patient, the general practitioner and the outpatient clinic: an operational study and a review. Psychological Medicine, 1, 312-325.

MALONEY, C. (1993) Who should refer to psychotherapy? Referrals to a regional service. Psychiatric Bulletin, 17. 352-354.

Office of Population Censuses and Surveys (1980) Classification of Occupations. London: HMSO.

- (1982) Census 1981 County Reports: Oxfordshire Part 2. London: HMSO.
PARRY, G. (1992) Improving psychotherapy services: applications of research, audit and evaluation. British Journal of Clinical Psychology. 31, 3-19.

Rrue, A. (1990) Cognitive-Analytic Therapy: Active Partictpation in Change (pp. 1-2). Chichester. John Wiley.

TUCKETT, D. (1976a) Becoming a patient. In An Introduction to Medical Sociology (ed. D. Tuckett), pp. 159-189. London: Tavistock.

- (1976b) Work. life-chances and life-styles. In An Introduction to Medical Sociology (ed. D. Tuckett). pp. 110-155. London: Tavistock.

TUDOR HART, J. (1971) The inverse care law. Lancet, 4 405412.

Wnulams, P. \& Clare, A. (1986) Psychiatry in general practice. In Essentials of Postgraduate Psychiatry leds P. Hill, R. Murray \& A. Thorley), pp. 597-617. London: Grune \& Stratton.

Christopher Maloney, Consultant Psychotherapist, Heatherwood Hospital, Ascot, Berkshire SL5 8AA

\section{Seminars in Clinical Psychopharmacology Edited by David J. King}

Psychopharmacology is a key both to the understanding of the biological basis of severe mental illness and to the rational use of drugs in clinical psychiatry. This book is an excellent introduction to an ever-expanding and fascinating subject, linking relevant basic neuropharmacology to clinical practice. It aims to bridge the gap between the theoretical basis for the mode of action of psychotropic drugs and guidance on their clinical use, and should increase interest in and understanding of the drugs widely used in clinical practice. $£ 20.00,544$ pp., 1995, ISBN 0902241737

Available from bookshops and from the Publications Department, Royal College of Psychiatrists, 17 Belgrave Square, London SW1X 8PG (Tel. 01712352351 extension 146)

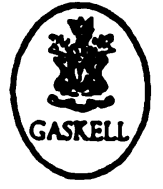

